\title{
Conflitos do outono de 2005 na França*
}

\author{
Didier Fassin \\ Tradução de Paulo Neves
}

$N$ ão é muito freqüente as ciências sociais - institucional e profissionalmente - reagirem a um fato social que toma uma forma de acontecimento. Temos em geral uma espécie de reticência a tratar da atualidade, que preferimos deixar aos jornalistas, reclamando para nós mesmos a distância e a duração: distância do olhar científico, duração da pesquisa etnográfica ou sociológica. Sob esse aspecto, a antropologia é exemplar: muito poucos de seus trabalhos tratam de acontecimentos, a descrição prevalece sobre a narração, o presente do intemporal e das regularidades é mais aceito que o passado simples do relato e das peripécias. $E$, mesmo que 0 tempo seja o objeto de nossas pesquisas, esse tempo é o da mudança social, ou seja, das mutações profundas e das transformações estruturais. $\mathrm{N}$ ão o do acontecimento, que tendemos a ver apenas como a espuma de mudanças sociais mais essenciais à nossa análise. $M$ as com os fatos que se produziram no final do mês de outubro e começo de novembro de 2005, e pela importância que adquiriram para a sociedade francesa - e mesmo para o mundo, pois foram mostrados espetacularmente pelos meios de comunicação em todo o mundo -, há uma certa reabilitação do acontecimento, não como uma realidade acessória entregue ao tratamento jornalístico, mas como uma realidade essencial, na medida em que revela fenômenos dissimulados ou ocultos. Esses conflitos podem, seguramente, ser compreendidos como uma prova de verdade.

* Este texto é a versão revisada de uma conferência pronunciada em 25 de janeiro de 2006 na École des $\mathrm{H}$ autes Études en Sciences Sociales[EH ESS], dentro de um ciclo intitulado "Pensar a crise das periferias". A versão filmada da conferência está dis ponível no sitewww.eh ess.fr. Posteriormente, essareflexão foi prolongada no quadro deuma obra coletiva: De la question socialeà la ques tion raciale? Représenter la sociétéfrançai se, sob a direção deD idier Fassin eEric Fassin (2006). 
M as o que éum acontecimento? 0 u, para dizer de outro modo: 0 queé que produz acontecimento nas violências urbanas que testemunhamos? D evemos aqui resistir ao fascínio das imagens de prédios em chamas, veículos queimados, jovens com máscara ninja e policiais de capacete que constituíram a iconografia mais difundida. D e minha parte, realizando pesquisas junto a uma brigada anticriminal de Paris e circulando à noite com a polícia numa das duas regiões onde as estatísticas de violências eram as mais el evadas, pude apenas constatar o contrasteentreo queal guns comentadores qualificavam de "guerra civil" e o que eu via, a saber, uma calma ordinária deperiferia, pontuada, na maioria das vezes, por incêndios esporádicos cujos autores praticamente haviam desaparecido quando a polícia chegava no local eque só muito excepcional mente ocasionavam confrontos, em geral sob a forma de veículos incendiados. Respondendo a uma de minhas perguntas sobre as violências observadas em seu distrito, o comissário principal de um dos supostos pontos quentes da cartografia dos conflitos que os meios de comunicação mostravam diariamente devolveu-me a pergunta: "D e que violência está falando? Se são veículos incendiados, de fato o número é maior que de costume. $\mathrm{M}$ as, se está falando de confrontos, praticamente nada aconteceu". 0 quemefoi confirmado a seguir pel os policiais da brigada anticriminal, que são evidentemente, por sua missão, os primeiros no front das violências. D evemosassim nosinterrogar sobrea produção midiática e política do acontecimento, e, é claro, sobre seus efeitos em termos de construção dos medos e, mais amplamente, de representações do mundo social e da relação com o outro interior, ao mesmo tempo próximo edistante, familiar e inquietante, novo avatar das "classes perigosas" de outrora.

Para voltar à questão inicial, o que produz acontecimento não é tal vez 0 número de veículos queimados e policiais feridos - que, evidentemente, participam de sua realidade. 0 que produz acontecimento é a separação de dois estados do mundo social, entre um "antes" eum "depois". Seosconflitos urbanos do outono de 2005 constituem um acontecimento, é porque hoj e não vemos mais a sociedade francesa exatamente da mesma forma, ou porquea sociedadefrancesa não sevêmais exatamenteda mesma forma. No centro dessa mudança deol har edessa nova reflexão estáa questão das discriminações raciais, de certo modo consagrada pelo discurso solene do presidente da República, que fez dela o ponto essencial de sua única intervenção televisada, mas que deu ensejo também a múltiplas matérias dejornalistase a numerosos exercícios de introspecção. Claro quejá se havia, antes, começado afalar dediscriminaçõesea preocupar-secom el as. H ouvetrabal hosde 
sociólogos - de Philippe Bataille eV éronique D e Rudder sobre o emprego, de Agnès Van Zanten sobre a escola e de Patrick Simon sobre a moradia. H ouve relatórios oficiais, a começar pelo Alto Conselho para a Integração, em 1998, emobilizações associativas, especialmenteo Gisti. Já havia o G eld (Grupo de Estudo e de Luta contra as D iscriminações), ao qual sucedeu a $\mathrm{H}$ alde (Alta Autoridade para a Luta contra as D iscriminações e para o Emprego); as Codac (Comissões D epartamentais sdeAcesso à Cidadania), transformadas em Copec (C omissões para a Promoção da I gual dade de 0 portunidades eda Cidadania), supostamente encarregadas das queixas de pessoas que sofreram discriminações; 0 114, número anônimo e gratuito pelo qual podiam ser ouvidas as vítimas e as testemunhas de discriminações raciais, e que aos poucos caiu em desuso; a lei que transferiu o encargo da prova, em matéria de discriminações, da vítima para o autor presumido, e a jurisprudênciaquepassou a incluir a discriminação indireta, ou seja, estatisticamenteestabelecida eindependentedequalquer intencionalidade. É verdade: em menos de uma década passamos de um silêncio total a um reconhecimento oficial. M as o tema permanecia relativamente confinado ao meio das ciências sociais e aos círculos político-administrativos. 0 que os livros dos pesquisadores e o trabal ho das instituições se esforçavam por fazer emergir, alguns incêndios espetaculares e al gumas violências relativamente contidas tornaram visível à grandemassa: a questão das discriminações raciais, namedida em que representa um desafio ao modelo republicano, tornou-se central no espaço público - não importando o quese pense dela.

O s conflitos das periferias, portanto, são um acontecimento no sentido de que estabelecem simbolicamente um antes e um depois na sociedade francesa contemporânea - o que a multiplicação dos comentários e das análises vem atestar. 0 confronto do modelo republicano e das discriminações raciais é agora um lugar-comum de nossa linguagem. As violências recentes, porém, não são o único elemento explicativo. Seria preciso também levar em conta a redescoberta da questão colonial relacionada à lei de fevereiro de $2005^{1}$, a reavaliação da história do tráfico de escravos, a reivindicação de uma memória da escravidão e a emergência de uma identidade negra por meio de uma mobilização associativa, elementos, todos esses, que suscitaram uma intensa polarização dos debates em torno das relações ambíguas da República com seu passado e seu presente. Sob esse aspecto, em vez de isolar os conflitos na gênese de uma "questão racial", caberia antes falar de configuração de acontecimentos, de um conjunto defatos significativos para a sociedade francesa de hoje.
1.Lei O rdinária2005102, sobre a igualdade de direitos e oportunidades (N.T.). 
Um lugar-comum, no entanto, não éuma verdade sociológica. E assim devemostornar a interrogá-lo com nossos instrumentos, isto é, à luz denossas investigações. Antes de fazer isso, gostaria de voltar uma última vez ao acontecimento em si. Em sua maior parte, os comentários políticos e as análises das ciências sociais relacionaram os conflitos com as desigualdades de que são vítimas certosjovens em termos deemprego, de moradia e, mais globalmente, de futuro. 0 u seja, estabeleceu-se naturalmente uma relação causal entre uma situação socioeconômica comprovada euma manifestação violenta de frustração. Essa explicação me parece parcial mente inexata: ela não permite compreender real mente os fatos que se produziram. 0 s conflitos não resultam de maneira determinista de uma realidade do mercado de trabal ho e das relações de produção. Conformeanalisou o historiador britânico E. P. T hompson a propósito das rebeliões de camponeses ingleses no século XVIII, o que está em causa não é só uma questão deeconomia política, mas uma questão deeconomia moral: assim como em todos os conflitos urbanos no último quarto de século na França, a violência é consecutiva à mortede adolescentes ou dejovens no quadro de choques com a polícia, isto é, de perseguições ou de brutalidades. D a mesma forma que os camponeses ingleses do sécul $\mathrm{XVIII}$, os joven franceses dos bai rros ditos em dificuldade aprenderam a tolerar um certo grau de discriminação, de exploração, de humilhação. M as é a ruptura desse frágil equilíbrio dos valores que gera a violência: quando há morte de um ou, no caso presente, de dois deles - e com mais razão quando se trata de jovens que não haviam cometido delito algum, ou com mais razão, enfim, quando o luto da família e dos amigos não é reconhecido - , é então que a exasperação se produz, porque se foi longe demais. 0 intolerável é menos a desigual dade social ou a discriminação racial do que a desval orização das vidas e a desqual ificação dos mortos, que são, é verdade, a conseqüência das primeiras. É a negação radical de justiça levada ao extremo, o não respeito às regras do próprio jogo desigual, que constitui o fator desencadeador das violências, tanto hoje como ontem. É importante analisar isso, caso contrário não se compreende por quê - se apenas a economia política estivesseem causa - não haveria uma guerra civil permanente. C aso contrário não se compreende, sobretudo, que a questão levantada por esses acontecimentoséa do Estado como detentor do monopólio da violência legítima que, nesses bairros considerados difíceis, passa a empregar uma violência ilegítima de maneira ordinária.

D e fato, os policiais e seus superiores, quando interrogados, justificam com freqüência o uso da força como uma necessidade diante da perda de 
autoridadegeneralizada, a dos pais, dosprofessores, das instituições, da própria polícia. C onvém certamenteinverter essa relação causal: éo uso injustificado e desproporcional da força - ao mesmo tempo brutalidade física e violência simbólica - que mina a autoridade do Estado e de suas instituições, pois esta é precisamente o que se impõe por si sem recurso à força. $\mathrm{N}$ um processo por violências policiais a que assisti no ano passado (violências contra dois homens, um turco e outro antilhano, ambos sem ligação com o caso no qual cerca de trinta policiais intervieram), os próprios acusados relataram à audiência que, no momento de lançarem sua expedição punitiva num bairro, seu comandante os estimulara, dizendo: "Perdemos a guerra da Argélia, não vamos recomeçar. D esta vez, nada de prisionei ros...". Percebe-se quanto, numa cena como essa, a autoridade do Estado vê-se prejudicada e quanto o passado colonial subjaz às discriminações raciais. Portanto, éa relação concreta com o Estado que está no princípio dos conflitos urbanos recentes.

D ito isso, convém voltar, no entanto, ao que torna tais fatos possíveis. Se a relação com a força política constitui o fator desencadeador, devemos então nos interrogar sobrequais são suas condições de possibilidade. É aqui que a questão das discriminações raciais obriga a pensar com novo interesse as questões mais antigas colocadas às ciências sociais pel as disparidades econômicas e pela segregação residencial: à classe e ao bairro como elementos que estruturam as desigualdades, estudados por Stéphane Beaud e M ichel Pialoux, cumpre agora acrescentar a atribui ção étnico-racial. Fazer uma leitura étnico-racial dos conflitos recentes envolve, com certeza, problemas delicados, pois essa é precisamente a maneira pela qual os conflitos foram qualificados, e portanto desqualificados, por comentadores como Alain Finkelkraut, que fala de "pogroms anti-republicanos" praticados por jovens "negroseárabes". M inha intenção écompletamente outra, como terão compreendido. $\mathrm{N}$ ão quero dizer que a revolta é étnico-racial, mas sim, ao contrário, que é um protesto contra a atribuição étnico-racial imposta a certas populações, e contra as discriminações que daí decorrem. Como outros já disseram, Emmanuel Todd, por exemplo, para ficar no registro de intelectuais não específicos, ela é um protesto republicano, portanto.

As discriminações oferecem aqui um instrumento conceitual ejurídico para pensar uma realidade evidentemente antiga à qual não se dava nome, mas que existia de fato. Podemos lembrar que uma discriminação é um tratamento desfavorável ligado ao uso de um critério ilegítimo - aqui em função da origem da pessoa, da cor de sua pele, da consonância de seu 
2. Azul-branco-vermeIho, as cores da bandeira francesa (N.T.).

3. Algo como "quebrapedras" (N.T.). patrônimo, da sua suposta religião. É essencial compreender que a discriminação, que éuma ruptura da igual dade de direito entre as pessoas, não é o racismo. Embora os dois sejam facilmente associados, existe um racismo sem discriminação, o do empregador que tem preconceitos contra africanos, mas que os contrata porque aprecia sua coragem e sua docilidade, assim como existem discriminações sem racismo, as do artesão que não recruta um aprendiz árabe por temer a reação de seus clientes. As agências de emprego aprenderam a decodificar essas formas múltiplas de associação entre discriminações e racismo nas ofertas que Ihes apresentam os empregadores, como observou o sociólogo O livier $\mathrm{N}$ oël: uns exigem os BBR (bleu-blancrouge ${ }^{2}$ ), isto é, que não sejam "pessoas de cor"; outros, ao contrário, precisam dos CLD (crèvela-dalle ${ }^{3}$ ), isto é, pessoas "dispostas ao serviço pesado", ou seja, dos países do Sul.

As discriminações raciais não são certamente novas: os imigrados e os estrangeiros foram suas vítimas ao longo de todo o século XX. Com freqüência eles consentiram, tendo interiorizado mais ou menos essa ilegitimidade. 0 fato novo, porém, é que hoje elas envolvem em massa franceses nascidos na França, que não compreendem que não sejam tratados como 0 restante dos franceses nascidos na França e que constatam que essa diferença de tratamento está ligada a preconceitos comuns sobre uma origem na qual são encerrados. N esse ponto, aqueles de meus colegas historiadores que continuam a pensar a situação atual em termos de imigração e a qualificar as formas contemporâneas de rejeição do outro em termos de "xenofobia" não perceberam essa mudança essencial, juntando-se assim, involuntariamente, aos responsáveis políticos que associaram conflitos e imigração. Claro que a xenofobia permanece, acentua-se mesmo sob al guns aspectos, mas os conflitos em questão dizem respeito basicamente a franceses autóctones vítimas de racismo e de discriminações.

Como compreender então a persistência etalvez o agravamento das discriminações raciais num país que há dois séculos constrói-se sobre uma ideologia um pouco apressadamente qualificada de republicana? I deologia fundada num tríplice princípio de igual dade, universalismo e assimilação, cada um desses três elementos parecendo padecer com as discriminações raciais, na medida em que estas são uma desigualdade de fato oposta a uma igualdade de direito, uma redução identitária que nega o universalismo e um fracasso do trabalho de assimilação. Contrariamente ao que se pensou por muito tempo, não se trata de um acidente da história, mas sim de uma contradição que sempre esteve presente na República. C aberia então 
percebêla por meio do conjunto do que se pode chamar, em vez de uma política da imigração relacionada a questões de cidadania, uma política da al teridade constitutiva da construção da nação. U ma política quepoderiaser seguida - e hoje isso se compreende melhor graças ao trabalho dos historiadores e dos antropólogos - atéo período colonial, com aquele encontro insólito entre a República francesa e seus indígenas, que ela procurou tratar simultaneamente, segundo a fórmula de $\mathrm{H}$ annah Arendt, como irmãos e como súditos, assimilando-os ao mesmo tempo que os separava.

H oje, a dialética da integração e da discriminação é, com certeza, uma herança dessa história, no núcleo do próprio Estado. $\mathrm{N}$ as cerimônias de naturalização que foram instituídas para dar mais solenidade, e às vezes mais calor, ao ato de entrega do documento às pessoas que obtêm a nacionalidade francesa - cerimônias sobre as quais realizei observações durante vários meses - , o representante do Estado opera o duplo gesto em que, de um lado, pronuncia o ingresso dessas pessoas na comunidadenacional, acompanhado de um diaporama sobre a história e os valores da França, e, de outro, relembra-lhes em seu discurso que elas são diferentes, não exatamente iguais e, com certeza, suspeitas de não conhecerem os val ores republicanos, insistindo no trabal ho que terão de realizar daí em diante sobre si mesmas para se tornarem dignas do que ele qualifica de "favor que vos concede a República".

Sabemos que a invocação desse modelo republicano foi o principal obstáculo ao reconhecimento da existência de discriminações raciais até o final dos anos de 1990. N omeá-las e aval iá-las era, por uma espécie de performatividade do discurso, fazêlas existir no espaço público e, por acréscimo, estigmatizar ainda mais os que eram suas vítimas. Era preferível, pois, silenciálas e trabalhar discretamente para uma melhor integração daquelas e daqueles que continuavam a ser vistos como estrangeiros, quando eram com freqüência franceses, ou como imigrados, quando geralmente haviam nascido na França. Q uanto menos se falasse deles, melhor as coisas andariam. E a denegação das discriminações raciais pelos que eram seus autores ou observadores podia mesmo encontrar um eco na recusa das próprias vítimas, que preferiam fazer-se esquecer. É esse pano de fundo de ocultação sob pretexto de benevolência, em uns, ede silêncio marcado deculpabilidade, em outros, que continua ainda operando nesse duplo movimento pelo qual mesmo os que se encarregaram de lutar contra as discriminações nas prefeituras e nas comunas, nas empresas e nos tribunais, não se convenceram totalmente da razão de ser de sua ação. Como compreender ainda hoje 
4. N atural do M agreb, Áfricado N orte (N .T.). essa recusa, no momento em que parece haver enfim um reconhecimento do fenômeno?

Primeira explicação: para muitos é difícil nomear o que constatam e mesmo aqueles de quem falam. H esita-se em dizer discriminações, há repugnância em qualificá-las de raciais. M istura-se com freqüência "estrangeiros", "imigrados" e "franceses nascidos na França" que, por falta de palavras, são designados então como "oriundos da imigração". D iz-se "jovens", como os empregadores que declaram que não os querem em sua empresa, para não dizer "pessoas de cor". D iz-se "magrebinos"4, como por ocasião dos conflitos de Perpignan em maio de 2005, para nomear pessoas com essa origem que têm nacionalidade francesa. Todos se lembram do próprio presidente da República, denunciando com vigor, em 14 de julho de 2004, os atos racistas e anti-semitas, e acrescentando: " $M$ uitos judeus, muçulmanos e mesmo franceses são vítimas de intoleráveis violências". As palavras traem assim nossas dificuldades de pensar essas situações. H á uma necessidade urgente, portanto, de clarificar nossa linguagem, isto é, de clarificar também nosso pensamento.

Segunda explicação: muitos desconhecem a realidade do que são as discriminações raciaiseo arsenal dequedispõem para combatêlas, mesmo que faça parte de sua missão lutar contra esse tipo de desigual dade. M uitas vezes elas são reduzidas aossimples atos ou palavras explicitamenteracistas, não se levando então em conta a maior partedas situações de discriminação defato, sejam elas diretas ou indiretas. Contudo, muitos fatos que os atores descrevem, equeeles não consideram como procedendo realmentedediscriminações, incluem-se nessa definição. $M$ as, ainda que elas sejam reconhecidas como tais, ignora-se com freqüência os instrumentos disponíveis para combatêlas. Essa constatação foi feita pela mi ssão de inspeção da I gas (Inspeção G eral dosAssuntosSociais) edaI GS (Inspeção G eral dosServiços): as comissões de defesa da cidadania, não obstante serem pedras angulares da política, conhecem geralmente muito mal os dispositivos institucionais eas disposições legislativas. Com isso, o recurso ao direito por processos penais ou civis, ou mesmo por meio denegociações com os produtores de discriminação para obter uma forma de reparação às vítimas, éraramente utilizado. Em realidade, a renúncia a recorrer ao direito, queéa forma mais ordinária detratamento das queixas e dos sinais de discriminação, estáligada tanto ao desconhecimento desse direito como, talvez ainda mais entre os que o conhecem, a um evitamento. Prefere-se não mais enviar certos jovens a certos empregadores a denunciar suas práticas, e isso, pensa-se, no interesse dos 
própriosjovens. Prefere-senão utilizar num tribunal o argumento do caráter racista de uma violência, porque se sabe que há o risco de os juízes não concordarem. Assim, as pessoas se privam muitas vezes do direito porque não crêem completamenteem sua forçanem em seus efeitos, pelo menos no curto prazo.

Terceira e última explicação: muitos não estão inteiramente convencidos da realidade das discriminações. Claro, estão prontos a admiti-las em suas formas extremas, mais brutais, explícitas. M as também consideram muitas vezes que as pessoas que se dizem vítimas tendem a cair na "vitimização", ou, ao contrário, justificam os que produzem discriminações porque eles têm, explicam, boas razões defazêlo. A desqual ificação das vítimas em nome da vitimização ea justificação das discriminações em nome de sua racionalidade constituem, portanto, dois elementos importantes de normalização dessas práticas. $\mathrm{N}$ ão discutirei o segundo elemento, para o qual toda uma corrente de estudos econômicos traz importantes luzes. Sublinharei apenas, a propósito do primeiro, que nada permite pensar que 0 reconhecimento recente das discriminações raciais no espaço público francês suscitou vocações vitimárias. M uito pelo contrário, a maioria daquelas e daqueles que foram objeto dessa forma de desigual dade quase não se queixaram, sobretudo por considerarem muito elevado o custo simbólico de admitirem-se discriminados pelo que são. Assim, antes de nos inquietarmos com o risco de vitimização, convém procurar responder às vítimas depois de ouvi-las e principal mente reconhecer os seus direitos, isto é, adotar uma verdadeira política do reconhecimento.

D e resto, os próprios analistas, entre os quais os pesquisadores em ciências sociais, utilizam-se dessas lógicas da recusa, especialmente quando comentam fenômenos e políticas para combatêlos. Convém estar atento a essa retórica que visa, no fim de contas, menos a justificar o não fazer nada do que mostrar os riscos que haveria em fazer al guma coisa. D aquilo que chamou uma retórica reacionária, Albert $\mathrm{H}$ irschman descreveu três modalidades principais, que ele estudou a propósito da resistência dos conservadores à extensão dos direitos civis, políticos e sociais desde o século XVIII, mas que seria fácil de retomar a propósito das reticências diante de uma política de luta contra as discriminações nas sociedades contemporâneas (a palavra reacionário deve ser entendida aqui para além de um simples posicionamento no espectro clássico, direita-esquerda, da representação política, mas sim como uma postura de reação ao que muda). 0 s três argumentos são em geral tanto mais eficazes quanto se apresentam em benefício 
mesmo daquilo que demolem. A tese do efeito perverso consiste em dizer que a luta política arrisca-se a produzir resultados contrários ao que se busca. A tese do esforço vão afirma que o quese empreende terá conseqüências mínimas e superficiais, ou mesmo nulas, em relação ao caráter estrutural dos problemas em causa. A tese do jogo perigoso sugere, enfim, que a ação buscada, mesmo seé desejável, induzirá mudanças bem mais graves do que aquilo que se pretende.

Essas três modalidades descrevem formas retóricas puras. Com muita freqüência, os argumentos inscrevem-se em discursos híbridos que misturam as três e outras mais. Poderíamos reler os argumentos opostos à discriminação positiva em função dessa tipologia: ela tem efeitos perversos, pois obriga a categorizar as pessoas, retomando os critérios que se quer combater; ela é um esforço vão, em relação aos problemas de desemprego, moradia, rendimentos, que são as verdadeiras questões; ela é um jogo perigoso, pois produz indivíduos desqualificados pelo simples fato de terem sido escolhidos segundo esses critérios. A esse tríptico retórico, dever-se-ia seguramente acrescentar um quarto elemento, específico ao contexto francês: 0 espantal ho da sociedade norte-americana e de seu comunitarismo.

Longe de mim a idéia defazer da discriminação positiva, ou melhor, das ações que visam a restabelecer uma igual dade de fato, a solução para combater as discriminações raciais - muito embora, no ensino superior e na pesquisa científica, eu esteja certo de que ela teria alguns efeitos benéficos. Sem desconhecer suas contradições esuas dificuldades, creio queela éum instrumento, entre outros, com um valor simbólico forte, e que provavelmente teria um efeito de desvelamento de nossas práticas e de impulso a nossas reformas. $M$ as nas periferias onde trabal ho e vivo, para os adolescentes e os jovens junto aos quais faço pesqui sas e que são amigos de meus filhos, sei 0 quanto as discriminações raciais estão ligadas às desigual dades econômicase à segregação residencial, e o quanto os três fenômenos a serem combatidos dependeriam de verdadeiras políticas de justiça social, das quais não constatamoshojesequer o início. Precisamos deixar depensar como incompatíveis os dois modelos quefundam ajustiça: 0 da desigual dadeque exigea redistribuição e o da alteridade que exige o reconhecimento.

M uitos comentadores falaram, a propósito dos conflitos recentes, de "revolta sem voz", de "violência sem discurso político"; parece-me, pelo contrário, que al guma coisa foi dita de nossa sociedade e que muitos ouviram. M omento raro, por certo, numa época marcada pela anestesia política. $\mathrm{N}$ ão deixemos, pois, que se percam os efeitos desse momento precioso 
em que o mundo social voltou a ser mais inteligível para nós, e em que 0 intolerável de al gumas desi gual dades voltou a nos afetar.

\section{Referências Bibliográficas}

Bataille, Phillippe. (1997), Le racisme au travail. Paris, La D écouverte.

Beaud, Stéphane \& Pialoux, Michel. (2003), Violences urbaines, violence sociale. Paris, Fayard.

De Rudder, Véronique; Poiret, Christian \& Vourc'H, François. (2000), L'inégalité raciste: I'universalité républicaineà l'épreuve. Paris, Presses universitai res de France.

Fassin, Didier. (2001), "The biopolitics of otherness. Undocumented foreigners and racial discrimination in the French public debate". Anthropology Today, 17 (1): 3-7.

. (2002), "L'invention française de la discrimination". RevueFançaise de Science Politique, 52 (4): 403-423.

FASSIN, Didier \& FASSIN, Eric. (2006), De la question sociale à la question raciale? Représenter la société française. Paris, La D écouverte.

H IRSCHMAN, Albert. (1991), The rhetoric of reaction. H arvard, H arvard U niversity Press.

N o ËL, O livier. (2006), "I déologie raciste et production de systèmes discriminatoires dans le champ de l'apprentissage". Travailler, 16.

Payet, Jean-Paul \& Van Zanten, Agnès. (1996), “L'école, les enfants del'immigration et des minorités ethniques". Revue Fançaise de Pédagogie, 117: 87-149.

SIMON, Patrick. (1998), "La discrimination: contexte institutionnel et perception par les immigrés". Hommes et M igrations, 1211: 49-67.

Thом Pson, E. P. (1980), The making of the English working class. 1a edição 1963. Londres, Penguin Books.

\section{Resumo}

Conflitos do outono de 2005 na França

As revoltas do outono de 2005 na França constituem, para além dos estragos cometidos (menos significativos do que se supõe), um verdadeiro acontecimento, já que cristalizaram problemas presentes mas ainda não percebidos, e geraram um limite temporal a partir do qual a sociedade muda o olhar sobre si mesma. U ma possível interpretação do acontecimento apresenta dois níveis. D e um lado, as circunstâncias que 0 desencadearam estão ligadas, como qualquer revolta ocorrida nos últimos 25 anos, a violências policiais que desestabilizaram a precária economia moral dos meios populares. D e outro lado, os fenômenos subjacentes envolvem uma forma particular 
de desigualdade que, durante muito tempo, a sociedade francesa se recusou a admitir: as discriminações raciais.

Palavras-chave: França; Revoltas; D iscriminações raciais; D esigualdade social.

\section{Abstract}

The 2005 autumn riots in France

The 2005 autumn riots in France may be considered a real event: it has given shape to issues not seen before as such yielding a time boundary which changed the way society regards itself. The suggested interpretation has two levels. On the one hand, the circumstances that have triggered off the events are related, as succeeds in any riots of the last 25 years, to police violence and the resulting unsettling in the precarious moral economy of the popular classes. $0 \mathrm{n}$ the other hand, the underlying phenomena are related to a particular form of inequality not acknowledge by French society: racial discriminations.

Keywords: France; Riots; Racial discriminations; Social inequality.

D idier Fassin é professor de Sociologia na Universidade Paris Nord e de Antropologia na EHESS de Paris. D iretor do CRESP, Centre de Recherche sur la Santé, le Social et le Politique. E-mail: dfassin@ehess.fr. 